\title{
A Discussion on Calculation Methods for Deepwater Wave Elements of Coastal Engineering
}

\author{
Zhang Lei ${ }^{1, a^{*}}$, Liu Jianbo ${ }^{1, b}$ \\ ${ }^{1}$ Technology Center of CCCC Second Harbor Engineering Co., Ltd, Wuhan 430040, China \\ awyyxzhanglei@163.com, ${ }^{b} 16635097 @ q q . c o m$
}

Keywords: coastal engineering; design wave elements; numerical simulation; design wind speed; West Kalimantan strait

Abstract. Taking the design wave elements prediction of West Kalimantan strait as an example, we adopted two methods, the numerical simulation method and the design wind speed method, to determine the deepwater wave elements of different return period. The results of two methods showed that there are some differences between the two predictions, but the difference is not significant. If there is long-term measured wind data, the design wind speed method is recommended for purpose of convenient.If not, wind and wave numerical simulation method is necessary to be used.

\section{Introduction}

In coastal engineering, wave data is necessary basic data, and it is important and fundamental to predict wave elements of different return period for engineering design. At present, there are three main methods to calculate deepwater return period wave elements. If there is long-term (at least 20 years) measured wave data, directional wave height with different accumulation frequencies can be used for frequency analysis to calculate wave elements of different return period ${ }^{[1]}$.If there isn't enough measured wave data, design wind speed method can be used ${ }^{[2]}$. If there is neither measured wave data nor measured wind data, we should pick high wind processes during recent 20 years and simulate wind and wave field by numerical mode ${ }^{[3-6]}$. Of all wind and wave numerical models, WRF and MiKE $21 \mathrm{SW}$ are widely used to simulate wind and wave field ${ }^{[7-9]}$.

The paper used wind and wave numerical simulation method and design wind speed method to calculate open-sea deepwater wave elements. Then we compared two methods and discussed the suitable method for calculating return period wave elements in different coastal engineering.

\section{General Sea Situation of Research Area}

This paper focused on West Kalimantan Strait, indonesia. Sea map and field survey results show that the water depth of $10 \mathrm{~m}$ is about $2 \mathrm{~km}$ from seacoast, then the submarine slope become gentle. The water depth of $15 \mathrm{~m}$ is about $15 \mathrm{~km}$ from seacoast. The region is located in the equator and belongs to a typical tropical monsoon climate, not affected by typhoon. The wind speed is generally small during monsoon. According to the data of the Ketapang airport meteorological station nearby, the statistical frequency of the measured wind speed can be seen in table 1. From the table, we can see that the region direction of prevailing wind and strong wind were both E direction, but the frequency of strong breeze $\left(8.7-10.8 \mathrm{~m} \cdot \mathrm{s}^{-1}\right)$ was 0 . 
Table 1 The statistical frequency of the measured wind speed

\begin{tabular}{ccccccccc}
\hline \multirow{2}{*}{ Speed $\left[\mathrm{m} \cdot \mathrm{s}^{-1}\right]$} & $<0$. & $0.5-2$. & $2.1-3$. & $3.6-5$. & $5.7-8$. & $8.7-10$. & $>=10$. & $\sum_{(\%}$ \\
& 5 & 1 & 6 & 7 & 7 & 8 & 8 & ) \\
\hline $\mathrm{N}$ & - & 1.9 & 2.6 & 1.7 & 0.2 & 0 & 0 & 6 \\
$\mathrm{NE}$ & - & 2.4 & 1 & 0.3 & 0 & 0 & 0 & 4 \\
$\mathrm{E}$ & - & 6.2 & 6 & 4.1 & 0.8 & 0 & 0 & 17 \\
$\mathrm{SE}$ & - & 2.1 & 2.4 & 1.8 & 0.2 & 0 & 0 & 6 \\
$\mathrm{~S}$ & - & 2.4 & 3.6 & 3 & 0.3 & 0 & 0 & 9 \\
$\mathrm{SW}$ & - & 1.3 & 1.2 & 0.6 & 0 & 0 & 0 & 3 \\
$\mathrm{~W}$ & - & 3.8 & 4.2 & 1.5 & 0.2 & 0 & 0 & 10 \\
$\mathrm{NW}$ & - & 2.1 & 2.6 & 1.4 & 0.1 & 0 & 0 & 6 \\
\hline$\sum(\%)$ & 38 & 22.1 & 23.6 & 14.4 & 1.9 & 0 & 0 & 100 \\
\hline
\end{tabular}

Usually, the wave height is small in dry season (from April to October), while large in the rainy season (from November to March of next year) under the influence of NE monsoon. in research area, there was a temporary wave station. According to measured data, the statistical frequency of directional wave height was listed in table 2. During the measured time, the direction of prevailing wave was WNW, and the frequency was $68.4 \%$. The direction of strong wave was WNW and NW.

Table 2 The statistical frequency of the measured wave height

\begin{tabular}{|c|c|c|c|c|c|c|c|c|}
\hline $\begin{array}{c}\text { Wave } \\
\text { Height [m] }\end{array}$ & $\begin{array}{c}0-0.4 \\
9\end{array}$ & $\begin{array}{c}0.5-0.9 \\
9\end{array}$ & $\begin{array}{c}1.0-1.1 \\
9\end{array}$ & $\begin{array}{c}1.2-1.4 \\
9\end{array}$ & $\begin{array}{c}1.5-1.9 \\
9\end{array}$ & $\begin{array}{c}2.0-2.9 \\
9\end{array}$ & $>=3.0$ & $\sum(\%)$ \\
\hline N-SW & 0 & 0 & 0 & 0 & 0 & 0 & 0 & 0 \\
\hline WSW & 0 & 0.65 & 0.1 & 0.1 & 0 & 0 & 0 & 0.85 \\
\hline W & 0.7 & 15.45 & 2.71 & 3.31 & 0.35 & 0 & 0 & 22.52 \\
\hline WNW & 0.7 & 37.06 & 15.3 & 11.53 & 3.61 & 0.2 & 0 & 68.41 \\
\hline NW & 0.1 & 3.51 & 1.3 & 1.96 & 1.1 & 0.25 & 0 & 8.22 \\
\hline NNW & 0 & 0 & 0 & 0 & 0 & 0 & 0 & 0 \\
\hline$\sum(\%)$ & 1.5 & 56.67 & 19.41 & 16.9 & 5.07 & 0.45 & 0 & 100 \\
\hline
\end{tabular}

\section{Wind and Wave Numerical Simulation Method}

Based on the reanalysis data of NCEP/NCAR, the meteorological modeling system WRF was adopted to simulate the wind field of research area. The wind field of $10 \mathrm{~m}$ above sea level was obtained with WRF, then wave filed of research area was simulated by MiKE $21 \mathrm{SW}$. The effectiveness of the model is verified by comparison and simulation results are in good agreement with the measured data. At last, return period wave elements was calculated by P-iii extreme value distribution analysis.

The Governing Equation of MiKE 21 SW. The governing equation of MiKE $21 \mathrm{SW}$ is the wave action balance equation ${ }^{[10]}$

$$
\frac{\partial}{\partial t} N+\frac{\partial}{\partial x} C_{x} N+\frac{\partial}{\partial y} C_{y} N+\frac{\partial}{\partial \sigma} C_{\sigma} N+\frac{\partial}{\partial \theta} C_{\theta} N=\frac{S}{\sigma}
$$

Where $N$ is wave action density, $\sigma$ is the relative angular frequency, $\theta$ is the wave direction, $C_{x}$, $C_{y}, C_{\sigma}, C_{\theta}$ are characteristic propagation speed in geographical space and spectral space, and $S$ is the energy source term, which represents the superposition of source function describing various physical phenomenon

$$
S=S_{i n}+S_{n 1}+S_{d s}+S_{b o t}+S_{\text {surf }}
$$


Here $S_{i n}$ represents the generation of energy by wind, $S_{n l}$ is the wave energy transfer due non-linear wave-wave interaction, $S_{d s}$ is the dissipation of wave energy due to whitecapping, $S_{b o t}$ is the dissipation due to bottom friction and $S_{\text {surf }}$ is the dissipation of wave energy due to depth-induced breaking.

The Validation of the Model. The calculation range of wave numerical model was from $7^{\circ} \mathrm{S}$ to $5^{\circ} \mathrm{N}$, from $102^{\circ} \mathrm{E}$ to $113^{\circ} \mathrm{E}$, as shown in Fig. 1 . Nonstructured triangular mesh was adopted, and the least element size was about $0.01^{\circ}, 1.1 \mathrm{~km}$.

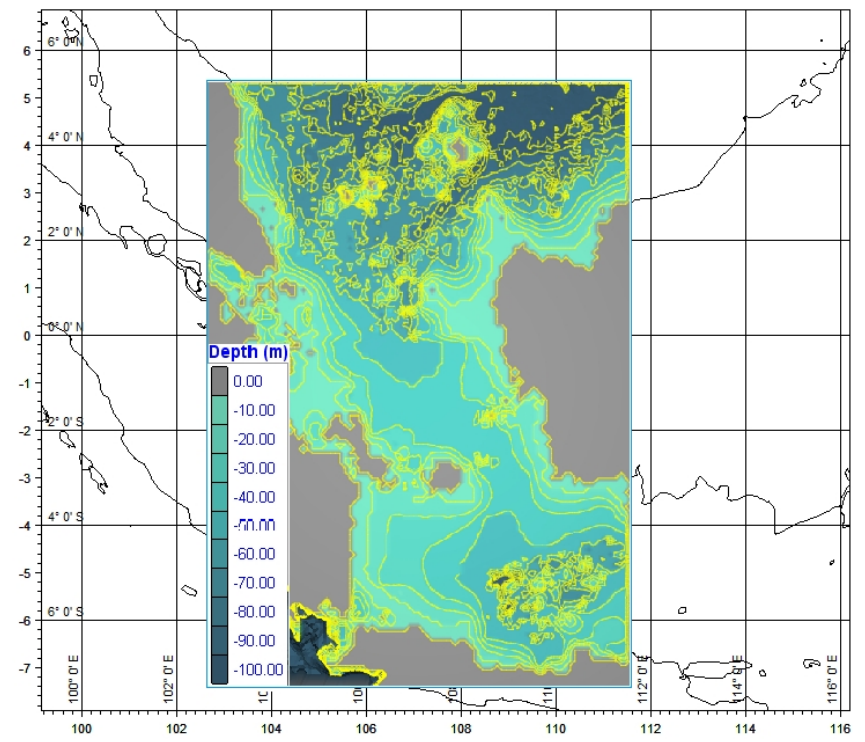

Fig. 1 The calculation range of wave numerical model

In research area, there was a temporary wave station, observed wave elements from Jan. 24, 2014 to Apr. 9, 2014. During the observation period, there were two strong winds, which could be used for validation of the model by comparing the calculated wave height with measured wave height (See Fig. 2 and Fig. 3). The figure shows that the calculated results are in good agreement with the observed results, so the model can be used to calculate the wave elements out research area.

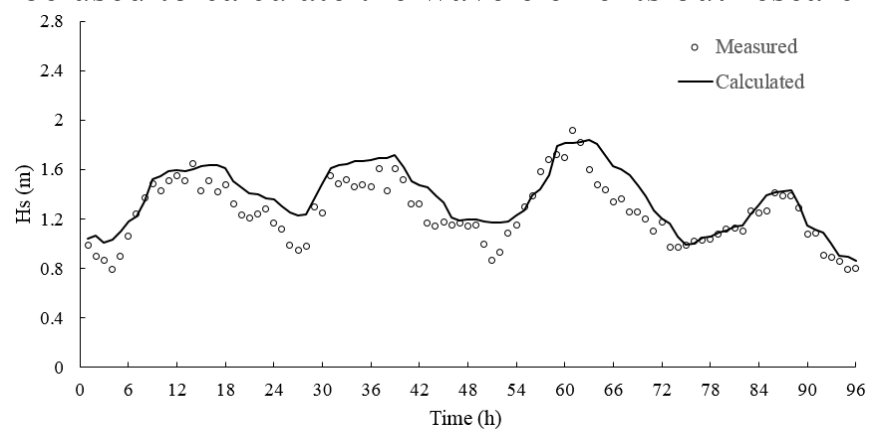

Fig. 2 The validation of $H_{s}$ (from 2014-1-19_12 to 2014-1-23_12)

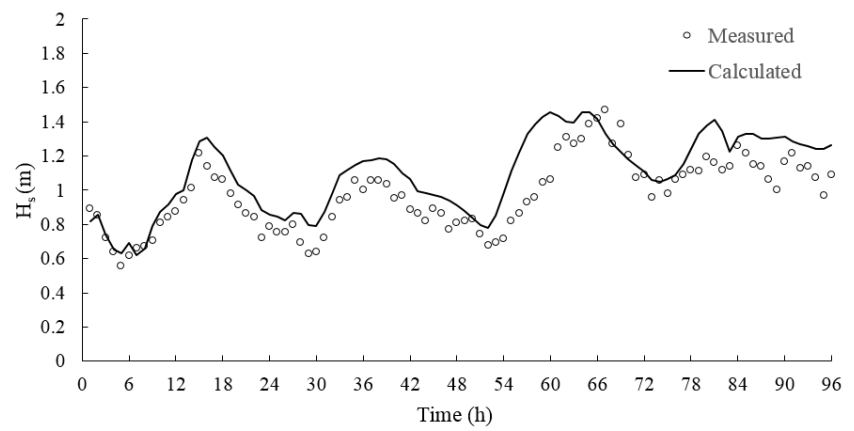

Fig. 3 The validation of $H_{s}$ (from 2014-1-28_12 to 2014-2-1_12) 
Calculated Results. Although the wind data showed that the region direction of prevailing wind and strong wind were both $\mathrm{E}$ direction, the direction of prevailing wave and strong wave were NW direction according to offshore data and the field measurement. NW wave, W wave and SW wave were chosen to calculated the design wave elements of different return period by simulating the wave field during high wind from 1995 to 2014 . A station on $-20 \mathrm{~m}$ contour was chosen to calculate wave elements, because the $-20 \mathrm{~m}$ contour of research area is straight relatively. The maximum wave height of each year in every direction were collected for P-iii extreme value distribution analysis, as showed in table 3. Wave elements of different return period of the station was obtained (see table 4).

Table 3 The maximum wave height of each year (from 1995 to 2014)

\begin{tabular}{|c|c|c|c|c|c|c|c|c|c|c|c|c|c|}
\hline \multirow{2}{*}{ Year } & \multicolumn{2}{|c|}{$\mathrm{NW}$} & \multicolumn{2}{|c|}{$\mathrm{W}$} & \multicolumn{2}{|c|}{ SW } & \multirow{2}{*}{ Year } & \multicolumn{2}{|c|}{$\mathrm{NW}$} & \multicolumn{2}{|c|}{$\mathrm{W}$} & \multicolumn{2}{|c|}{ SW } \\
\hline & $H_{s}[\mathrm{~m}]$ & $T[\mathrm{~s}]$ & $H_{s}[\mathrm{~m}]$ & $T[\mathrm{~s}]$ & $H_{s}[\mathrm{~m}]$ & $T[\mathrm{~s}]$ & & $H_{s}[\mathrm{~m}]$ & $T[\mathrm{~s}]$ & $H_{s}[\mathrm{~m}]$ & $T[\mathrm{~s}]$ & $H_{s}[\mathrm{~m}]$ & $T[\mathrm{~s}]$ \\
\hline 1995 & 1.77 & 5.67 & 2.24 & 6.36 & 1.41 & 5.12 & 2005 & 1.73 & 5.19 & 1.89 & 4.95 & 1.95 & 5.47 \\
\hline 1996 & 1.62 & 5.42 & 2.21 & 6.06 & 1.89 & 5.57 & 2006 & 1.73 & 6.00 & 1.89 & 6.61 & 1.95 & 5.35 \\
\hline 1997 & 1.76 & 5.80 & 1.35 & 4.81 & 1.20 & 4.21 & 2007 & 2.42 & 6.21 & 2.36 & 6.25 & 1.39 & 4.63 \\
\hline 1998 & 1.82 & 5.53 & 1.90 & 5.49 & 1.70 & 5.31 & 2008 & 2.32 & 5.96 & 2.16 & 5.75 & 1.45 & 4.88 \\
\hline 1999 & 1.87 & 5.73 & 2.28 & 6.18 & 1.33 & 4.85 & 2009 & 2.31 & 5.83 & 1.97 & 5.79 & 2.09 & 5.72 \\
\hline 2000 & 1.82 & 5.55 & 2.06 & 5.42 & 1.60 & 4.67 & 2010 & 2.30 & 6.06 & 1.94 & 5.61 & 1.50 & 4.68 \\
\hline 2001 & 2.61 & 6.51 & 1.98 & 5.46 & 1.99 & 5.46 & 2011 & 2.49 & 6.08 & 2.09 & 5.96 & 1.94 & 5.50 \\
\hline 2002 & 1.56 & 5.14 & 2.08 & 5.53 & 1.51 & 4.40 & 2012 & 2.48 & 6.09 & 1.51 & 4.91 & 1.16 & 3.57 \\
\hline 2003 & 3.02 & 6.47 & 2.87 & 6.30 & 1.85 & 5.07 & 2013 & 2.31 & 5.75 & 2.23 & 6.11 & 2.06 & 5.82 \\
\hline 2004 & 1.75 & 5.24 & 2.56 & 6.29 & 1.91 & 5.45 & 2014 & 1.97 & 5.80 & 2.02 & 5.46 & 1.76 & 5.24 \\
\hline
\end{tabular}

Table 4 Wave elements of different return period calculated by numerical simulation

\begin{tabular}{ccccccc}
\hline Return & \multicolumn{2}{c}{$\mathrm{NW}$} & \multicolumn{2}{c}{$\mathrm{W}$} & \multicolumn{2}{c}{$\mathrm{SW}$} \\
\cline { 2 - 7 } Period & $H_{s}[\mathrm{~m}]$ & $T[\mathrm{~s}]$ & $H_{s}[\mathrm{~m}]$ & $T[\mathrm{~s}]$ & $H_{s}[\mathrm{~m}]$ & $T[\mathrm{~s}]$ \\
\hline $100 \mathrm{a}$ & 3.37 & 6.89 & 3.08 & 7.25 & 2.6 & 6.65 \\
$50 \mathrm{a}$ & 3.17 & 6.75 & 2.93 & 7.05 & 2.46 & 6.43 \\
$25 \mathrm{a}$ & 2.96 & 6.59 & 2.78 & 6.83 & 2.32 & 6.19 \\
$2 \mathrm{a}$ & 2.02 & 5.78 & 2.04 & 5.73 & 1.64 & 5 \\
\hline
\end{tabular}

\section{Design Wind Speed Method}

The Method of Calculating Wave Elements by Wind. To calculate wind wave elements, the wind speed must be transferred from land to sea by land-sea correction and altitude correction. The influence of buildings, island and land should be considered to determine fetch length.

When $d / U^{2}>0.2$, which means the water depth $d$ is deep situation, the wind wave elements formula is given as below

$$
\begin{gathered}
\frac{g H_{1 / 3}}{U^{2}}=5.5 \times 10^{-3}\left(\frac{g F}{U^{2}}\right)^{0.35} \\
\frac{g T_{1 / 3}}{U}=0.55\left(\frac{g F}{U^{2}}\right)^{0.233} \\
\frac{g F_{\min }}{U^{2}}=0.012\left(\frac{g t}{U}\right)^{1.3}
\end{gathered}
$$

Where $g$ is acceleration of gravity $\left(\mathrm{m} / \mathrm{s}^{2}\right), U$ is wind speed $(\mathrm{m} / \mathrm{s}), F$ is fetch length $(\mathrm{m})$ and $t$ is wind time.

Wind data in this paper was measured by Manokwari airport meteorological station. The anemometer position was $3 \mathrm{~m}$ above land and the wind speed was average value in $10 \mathrm{~min}$. The 
calculation station was $2 \mathrm{~km}$ away from coast. Land-sea correction formula and altitude correction formula of wind speed were used to revise wind speed

$$
\begin{gathered}
\left(U_{\text {land }}\right)_{10}=1.22\left(U_{\text {land }}\right)_{3} \\
\left(U_{\text {sea }}\right)_{10}=1.1\left(U_{\text {land }}\right)_{10} \\
U=1.103\left(U_{\text {sea }}\right)_{10}
\end{gathered}
$$

Calculated Results. Collected the maximum wind speed of each year using the Manokwari airport meteorological station wind data from 1992 to 2012, then calculated return period wind speed by P-iii distribution analysis (see table 5). The Chinese standard recommended method was adopted to predict wind wave elements. The wind speed in Eq. 3, Eq. 4 and Eq. 5 is return period wind speed, which has already listed in table5, and wave elements of different period can be seen in table 6 .

Table 5 Wind speed of different return period (unit: $\mathbf{m} \cdot \mathrm{s}^{-1}$ )

\begin{tabular}{cccc}
\hline Return Period & NW & W & SW \\
\hline $100 \mathrm{a}$ & 19 & 17.9 & 17.4 \\
$50 \mathrm{a}$ & 18.4 & 17.3 & 16.9 \\
$25 \mathrm{a}$ & 17.8 & 16.7 & 16.5 \\
$2 \mathrm{a}$ & 14.4 & 13.9 & 13.6 \\
\hline
\end{tabular}

Table 6 Wave elements of different return period calculated by design wind speed

\begin{tabular}{ccccccc}
\hline Return & \multicolumn{2}{c}{ NW } & \multicolumn{2}{c}{ W } & \multicolumn{2}{c}{ SW } \\
\cline { 2 - 7 } Period & $H_{s}[\mathrm{~m}]$ & $T[\mathrm{~s}]$ & $H_{s}[\mathrm{~m}]$ & $T[\mathrm{~s}]$ & $H_{s}[\mathrm{~m}]$ & $T[\mathrm{~s}]$ \\
\hline $100 \mathrm{a}$ & 3.22 & 6.4 & 2.74 & 6.14 & 2.68 & 6.08 \\
$50 \mathrm{a}$ & 3.06 & 6.26 & 2.59 & 5.99 & 2.52 & 5.95 \\
$25 \mathrm{a}$ & 2.88 & 6.12 & 2.45 & 5.85 & 2.43 & 5.82 \\
$2 \mathrm{a}$ & 2.2 & 5.7 & 1.83 & 5.35 & 1.8 & 5.31 \\
\hline
\end{tabular}

\section{Comparison of Two Method}

Two different return period wave elements was obtained with wind wave numerical simulation method and design wind speed method. For ease of comparing, two method results were listed in table 7.

\begin{tabular}{|c|c|c|c|c|c|c|c|}
\hline \multirow{2}{*}{$\begin{array}{l}\text { Return } \\
\text { Perion }\end{array}$} & \multirow{2}{*}{ Method } & \multicolumn{2}{|c|}{ NW } & \multicolumn{2}{|c|}{ W } & \multicolumn{2}{|c|}{ SW } \\
\hline & & $H_{s}[\mathrm{~m}]$ & $T[\mathrm{~m}]$ & $H_{s}[\mathrm{~m}]$ & $T[\mathrm{~m}]$ & $H_{s}[\mathrm{~m}]$ & $T[\mathrm{~m}]$ \\
\hline \multirow{2}{*}{$100 \mathrm{a}$} & $\mathrm{i}$ & 3.37 & 6.89 & 3.08 & 7.25 & 2.6 & 6.65 \\
\hline & ii & 3.22 & 6.4 & 2.74 & 6.14 & 2.68 & 6.08 \\
\hline \multirow{2}{*}{$50 \mathrm{a}$} & $\mathrm{i}$ & 3.17 & 6.75 & 2.93 & 7.05 & 2.46 & 6.43 \\
\hline & ii & 3.06 & 6.26 & 2.59 & 5.99 & 2.52 & 5.95 \\
\hline \multirow{2}{*}{$25 \mathrm{a}$} & i & 2.96 & 6.59 & 2.78 & 6.83 & 2.32 & 6.19 \\
\hline & ii & 2.88 & 6.12 & 2.45 & 5.85 & 2.43 & 5.82 \\
\hline \multirow{2}{*}{$2 a$} & $\mathrm{i}$ & 2.02 & 5.78 & 2.04 & 5.73 & 1.64 & 5 \\
\hline & ii & 2.2 & 5.7 & 1.83 & 5.35 & 1.8 & 5.31 \\
\hline
\end{tabular}

Table 7 The comparison of two method results

(Method $\mathrm{i}$ is Wind and Wave Numerical Simulation Method; Method ii is Design Wind Speed Method)

The table shows that return period wave elements of two method there are some differences between the two results, but the difference is not significant. For the NW and $\mathrm{W}$ direction, $H_{s}$ calculated by method $\mathrm{i}$ is greater than method ii. The maximum difference is $0.34 \mathrm{~m}$ for $\mathrm{W}$ direction wave 100 -year return period, which is $3.08 \mathrm{~m}$ given by method i, $2.74 \mathrm{~m}$ given by method ii. However, for the SW direction $H_{s}$ calculated by method ii is greater, and the maximum difference is $0.16 \mathrm{~m}$ for 
2-year return period. In general, wave period and wave height are positive related, so the wave period has similar laws with wave height.

\section{Conclution}

Varied method could be used to calculate return period wave elements in coastal engineering. This paper adopted two method to calculate return period wave elements of West Kalimantan strait. Method I was wind wave numerical simulation. To collecting annual maximum wave height and wave period in 20 years, the wind field and wave field of research area during high wind were simulated by numerical simulation model. With P-iii distribution analysis, return period wave elements can be acquired. Method ii was design wind speed method, which calculating wave elements by wind. Return period wind speed was calculated with the wind data of land meteorological station, and revised by land-sea correction and altitude correction. With the wind wave elements formula, return period wave element could be calculated. Both methods have advantages and disadvantages. Method i don't need long term measured data but the simulation calculation process is much more complicated. Method ii requires at least 20 years measured wind data, but is simpler to use. If there is long term measured wind data, design wind speed method is recommended for purpose of convenient. If not, wind and wave numerical simulation method have to be used. This paper is supported by the applied basic research project of the Ministry of Transport (Project number: 2013319759060).

\section{References}

[1] CCCC First Harbor Consultants Co. Ltd., Code of Hydrology for Sea Harbor, first ed. China Communications Press, Beijing, 2013.

[2] H. M. Xu, An analysis on the influence of wind to wind wave computative results in shallow water, Journal of Waterway and Harbour, 4 (1997) 42-46.

[3] M. G. Li, H. Xiao, Methods for determining open-sea deepwater wave factors, Port \& Waterway Engineering, 7 (2010) 1-5.

[4] S. W. Li, C. Liang, Q. Zhuang, Application of SWAN model in onshore design wave factors calculation, Port Engineering Technology, 2 (2012) 5-7.

[5] W. W. Song, G. P. Chen, S. C. Yan, Wave parameters analysis of different return period in the open sea with a hindcast model of typhoon waves, Port \& Waterway Engineering, 1 (2013) 51-54, 75.

[6] Y. Zhou, Wind and Wave Analysis of Qingshui bay based on WRF and SWAN model, Unpublished MCE dissertation, Ocean University of China.

[7] G. Fu, C. P. Yang, A discussion on calculation methods of design wave elements of coastal engineering: Taking the prediction of the design wave elements of Rudong artificial island as an example, Port \& Waterway Engineering, 3 (2010) 42-46.

[8] W. H. Li, G. Fu, C. P. Yang, Prediction of design wave elements of coastal engineering by history typhoon weather charts method, Port \& Waterway Engineering, 7 (2012) 36-42.

[9] W. Y. Wang, Q. Q. He, P. F. Zhou, Numerical simulation of wave in the Nanri islands Sea of Fujian, Marine Forecasts, 5 (2013) 26-30.

[10] DHi, Mike 21 spectral wave module scientific documentation, Denmark: DHi Group, (2009). 